\title{
Clear plastic drapes for aerosol-generating medical procedures in COVID-19 patients: questions still remain
}

\author{
Ryan Vincent William Endersby, BSc, MD, FRCPC (10) Adam Oscar Spencer, BSc, \\ MSc, MD, FRCPC · Esther Ching Yee Ho, BSc, MD, FRCPC - David Howard Goldstein, MB, \\ BCh, BAO, MSc, FRCPC $\cdot$ Edward Schubert, BSc, MD, FRCPC
}

Received: 27 April 2020/Revised: 29 April 2020/Accepted: 29 April 2020/Published online: 11 May 2020

(C) Canadian Anesthesiologists' Society 2020

To the Editor,

We would like to thank Matava et al. for their interesting work on the use of three-panel clear plastic draping during a simulated cough. ${ }^{1}$ Their design describes a possible method to minimize droplet and aerosol contamination during aerosol-generating medical procedures (AGMP). In their experimental model, Matava et al., used Glo Germ ${ }^{\mathrm{TM}}$ (Glo Germ Company, Moab, UT, USA) to simulate both droplet and aerosol spread. Most aerosols are less than $1 \mu \mathrm{m}$ in diameter and are not visible to the human eye. ${ }^{2}$ Therefore, the experiment suggests more effective containment of droplet spread using the three-panel draping technique, but we believe it is difficult to draw conclusions regarding any impact on aerosol containment.

With designs predicated on aerosol containment during AGMP, we have concerns that previously contained aerosols may subsequently be released upon removal of the drapes. Accordingly, Matava et al. suggest careful removal of the drapes to avoid generating or perhaps more importantly, further dispersing aerosols. It would be useful to identify evidence-based strategies for drape removal that minimize aerosol spread. We believe adding closed circuit suction under the drape either during or after AGMP and prior to removal of the drapes may help reduce aerosols present under the drape. A significant drawback to an unsupported drape system is that the drapes impede the

R. V. W. Endersby, BSc, MD, FRCPC ( $)$.

A. O. Spencer, BSc, MSc, MD, FRCPC

E. C. Y. Ho, BSc, MD, FRCPC - D. H. Goldstein, MB, BCh,

BAO, MSc, FRCPC · E. Schubert, BSc, MD, FRCPC

Department of Anesthesia, Perioperative and Pain Medicine,

University of Calgary, South Health Campus, Calgary, AB,

Canada

e-mail: ryan.endersby@gmail.com dexterity required for all aspects of airway management including preoxygenation, bag-mask ventilation (if necessary), intubation, and awake extubation. As well, challenges with airway management may in turn lead to a partial removal or lifting of the over-head top drape negating the protective effect of the drape. Finally, we would also suggest that the disposal of the drapes be done by a healthcare worker (HCW) wearing appropriate personal protective equipment.

We believe that experimental models should be employed to analyze, with greater fidelity, the behaviour of aerosols to help address these questions. Thus, while we generally agree with Matava et al. that barrier strategies could increase safety for HCW performing AGMP during the coronavirus disease pandemic, they should first be tested more thoroughly to ensure safe clinical application.

Disclosures None.

Funding statement None.

Editorial responsibility This submission was handled by Dr. Hilary P. Grocott, Editor-in-Chief, Canadian Journal of Anesthesia.

\section{References}

1. Matava CT, Yu J, Denning S. Clear plastic drapes may be effective at limiting aerosolization and droplet spray during extubation: implications for COVID-19. Can J Anesth. 2020. DOI: https://doi. org/10.1007/s12630-020-01649-w.

2. Zayas G, Chiang MC, Wong E, et al. Cough aerosol in healthy participants: fundamental knowledge to optimize droplet-spread infectious respiratory disease management. BMC Pulm Med. 2012. DOI: https://doi.org/10.1186/1471-2466-12-11.

Publisher's Note Springer Nature remains neutral with regard to jurisdictional claims in published maps and institutional affiliations. 